\title{
Attitudes of Primary Pregnant Women Toward Preference of Birth Method in Dezful, Iran: A Cross-Sectional Study
}

\author{
Mahnaz Nosratabadi ${ }^{1}$, Nasrin Sarabi $^{2}$, Leila Masoudiyekta ${ }^{2}$, Zahra Abbaspoor $^{3}$ \& Aziz Kassani ${ }^{4}$ \\ ${ }^{1}$ Department of Midwifery, School of Nursing and Midwifery, Dezful University of Medical Sciences, Dezful, \\ Iran \\ ${ }^{2}$ Department of Nursing, School of Nursing and Midwifery, Dezful University of Medical Sciences, Dezful, Iran \\ ${ }^{3} \mathrm{PhD}$ in Reproductive Health, Associate Professor, Department of Midwifery, Reproductive health promotion \\ Research Center, Ahvaz Jundishapur University of Medical Sciences, Ahvaz, Iran \\ 4 Assistant professor of Epidemiology, Department of Community Medicine. School of Medicine, Dezful \\ University of Medical Sciences, Dezful, Iran \\ Correspondence: Mahnaz Nosratabadi, Department of Midwifery, School of Nursing and Midwifery, Dezful \\ University of Medical Sciences, Dezful, Iran.
}

Received: January 30, 2021; Accepted: April 23, 2021; Published: April 25, 2021

\begin{abstract}
Introduction: Choosing the birth method is a major issue for pregnant women that is affected by multifaceted physiological, psychological and socio-cultural factors.

$\operatorname{Aim}(\mathbf{s}):$ The aim research was performed to explore factors influencing pregnant women's attitude toward birth method.

Methods: This is a cross-sectional study on 220 healthy nulliparous pregnant women with uncomplicated pregnancies without any contraindication for vaginal birth in Medical Centers of Dezful, in the south west of Iran. Data collection tool was a questionnaire for factors affecting the choice of delivery method. Differences in attitude were compared between two groups of natural vaginal delivery preference and cesarean delivery preference. Statistical analysis was performed with SPSS Version 16.0 statistic software package. Descriptive statistics were used to report percentages, mean, and standard deviation, and t-test, chi-square were applied to analyze the data.
\end{abstract}

Results: During the study period, 206 primary pregnant women were examined to determine the attitudinal influencing factors the birth method preference. 131 women $(64 \%)$ chose the natural delivery method and 71 women $(36 \%)$ chose the cesarean delivery method. In addition, the results showed a statistically significant difference between the two groups regarding the general attitude of the participants towards natural delivery (164.43 in the normal vaginal delivery (NVD) group versus 134.50 in the cesarean section (CS) group (p<0.001)).

Conclusion: There is a direct relationship between the attitude of pregnant women towards vaginal birth and the tendency to normal vaginal delivery and cesarean section. Also, according to the results of the study of 8 components of attitudes, counseling sessions and prenatal training sessions can be identified based on counseling needs and be guided counseling sessions more purposefully.

Keywords: Attitude, Pregnant Women, Delivery, Cesarean Section

\section{Introduction}

Choosing the birth method is a major issue for pregnant women that is affected by multifaceted physiological, psychological and socio-cultural factors [1]. Choosing the birth method is a convenient, safe, and secure way for the mother to understand her baby's safety and comfort. This feeling is often shaped by emotional evaluations and judgments, and sometimes informed by beliefs, attitudes, experiences and information gained about the delivery method [2]. In recent decades, advances have been made in the development of human science and technology with the help of surgery in cases where the mother or fetus dies danger helped save them. Cesarean delivery has been one of the great human achievements and it has saved a lot of mothers and baby lives, but its application has increased alarmingly in recent decades [3]. The global concern about CS rates is reasonable. Studies have shown that maternal and prenatal mortality can be prevented by CS. Nonetheless, no evidence reveals the advantageous of the procedure for women or infants where it is unnecessary. CS is linked with short- and long-term risks 
extending beyond the present delivery and influencing the future pregnancies. Furthermore, the increased CS rates are apparently unmanageable without any signs of slowing down. This situation is intensified by uncertain causes of the increases developing as a complex multifactorial labyrinth including health systems, health care providers, women, societies, and even fashion and media [4-8]. Finally, non-clinical interventions to decrease needless CS have revealed restricted success up to now. Accordingly, a meeting was held by WHO in Geneva, Switzerland, on 8-9 October 2014 for 1) setting the current WHO position on the CS rate or range for best maternal and perinatal results at population level, and 2) approving on a proposal for a tool for monitoring CS rates at facility level [9]. According to the suggestions of the World Health Organization, the caesarean section rate should not exceed 10$15 \%$ of the labors [10]. According to a systematic review and an ecological analysis at population level, CS rates higher than $10 \%$ were not linked with decreased maternal and newborn mortality rates [9]. Several factors affect increased CS rate such as fear of childbirth, fear of lack of control over the childbearing events, fear of pain, the mother's choice, and the lack of knowledge regarding the CS drawbacks and vaginal delivery benefits as well as women's negative attitudes towards their preceding vaginal delivery. Moreover, the psychological factors such as fear, depression and anxiety are believed to be significantly involved in birth method selection [11]. Promoting maternal health requires understanding many complex factors involved in choosing the type of childbirth, and this can be achieved through consideration of women's beliefs, values and customs and understanding the impact of cultural factors on the choice of childbirth and maternal health [12]. Given the increased prevalence of cesarean section and extensive studies conducted around the world, one of the ways to reduce cesarean delivery without indication is to identify the causes and factors affecting the choice of delivery method, especially cesarean section. This paper aims at determining the causes and components affecting the choice of delivery method.

\section{Materials and Methods}

The current research is a cross-sectional descriptive and analytical study performed in six Health Centers in Dezful, in the south west of Iran from January to June 2019. Sampling was done by two-stage clustering method. At first, six Health Centers in Dezful were selected by simple random sampling and then samples were randomly selected from each health center using random number table. In this study, the sample size involved 204 eligible pregnant women. Based on the probable rate of attrition, 220 pregnant women were selected.

Inclusion criteria included age range of 18-35 years, height over $145 \mathrm{~cm}$, weight range of 50-90 kg, first pregnancy, gestational age of 28 weeks and consent and participation of pregnant women to participate in the study. Exclusion criteria included placental problems, diagnosis of multiple pregnancies, high-risk pregnancy (preeclampsia, diabetes, uncontrolled gestational diabetes, pre-term labor, fetal intrauterine death, etc.), having a history of infertility and contraindication for normal vaginal birth.

Data collection tool was a questionnaire of attitude factors affecting the choice of delivery method that was designed in 2014 by Abbaspour et al. [2]. This is a two-part questionnaire; the first part contains 15 items that show the demographic characteristics and preference of the birth method. The second part contains 68 items that show the attitudinal factors influencing the choice of birth method. This questionnaire covers 8 areas of choice of delivery method including: 1- Beliefs and attitudes, 2- Mental, sexual and physical patterns, 3- Fear of childbirth, 4- Overall confidence, 5- Social-cultural norms, 6- Trust the midwife, 7- Performance and personal choice, and 8. Sources of Influence. The questionnaire is based on the Likert scale According to the type of options or Likert questionnaires, the score questionnaire was divided into three groups: negative attitude towards natural childbirth and interest in cesarean section (113-68), neutral attitude (159-114) and positive attitude towards natural childbirth (204-160). That the increase in score indicated an increase in the desire to have a normal vaginal delivery. The questionnaires were completed after informed consent and assurance of the participants to keep their information confidential with the questionnaire guidance and self-report by the participants. The reliability of the questionnaire was determined by Cronbach's alpha coefficient of 0.889 and intra-class correlation coefficient of 0.73 with confidence interval (0.5-0.86). From 220 eligible participants, 206 completed and returned the questionnaires. After completing the study, the data were analyzed using SPSS software (Version 16). Descriptive statistics were used to report percentages, mean, and standard deviation, and t-test, chi-square were applied to analyze the data. $P$ value less than 0.05 was considered significant. The research ethics committee of Dezful University of Medical Sciences, Dezful, Iran (IR.DUMS.REC.1397.045), approved ethical issues of the study. Furthermore, all participant provided us with informed consent (oral and written).

\section{Results}

During the study period, 206 primary pregnant women were examined to determine the attitudinal influencing factors the delivery method preference. No differences were detected in terms of the socio-demographic 
characteristics between the between groups of preferred natural delivery method and preferred cesarean delivery method (Table 1).

131 women (64\%) chose the natural delivery method and 71 women $(36 \%)$ chose the cesarean delivery method. Also, the results of independent t-test revealed a statistically significant difference between the two groups regarding the general attitude of the participants towards natural delivery (164.43 in the normal vaginal delivery (NVD) group versus 134.50 in the cesarean section (CS) group $(\mathrm{p}<0.001)$ ) (Table 2).

There were statistically significant differences in the areas of belief $(\mathbf{4 6 . 7 7}$ in the NVD group versus $\mathbf{4 0 . 0 3}$ in the CS group $(\mathrm{p}<0.001)$ ), fear of childbirth $(\mathbf{1 5 . 5 2}$ in the NVD group versus 11.15 in the CS group $(\mathrm{p}<0.002)$ ), mental-sexual and physical concepts (31.40 in the NVD group versus $\mathbf{2 5 . 0 8}$ in the CS group $(\mathrm{p}<0.001))$, sociocultural norms (22.94 in the NVD group versus 20.60 in the CS group $(\mathrm{p}<0.001))$, all-round confidence $(23.98$ in the NVD group versus 15.25 in the CS group $(\mathrm{p}<0.002)$ ), trust in the delivery agent $(\mathbf{5 . 4 3}$ in the NVD group versus 4.61 in the CS group $(\mathrm{p}<0.001))$, performance and personal choice $(\mathbf{8 . 2 7}$ in the NVD group versus $\mathbf{7 . 7 5}$ in the CS group $(\mathrm{p}<0.004))$. Nevertheless, for the influential sources, there was no significant difference $(10.13$ in the NVD group versus $\mathbf{1 0 . 0 4}$ in the CS group $(\mathrm{p}=\mathbf{0 . 7 5 2})$ ) (Table 3$)$.

Table 1. Demographic Factors of Pregnant Women in Two groups of Preference of natural childbirth and cesarean section

\begin{tabular}{|c|c|c|c|c|c|c|}
\hline \multirow{2}{*}{\multicolumn{2}{|c|}{$\begin{array}{c}\text { Groups } \\
\text { Variables }\end{array}$}} & \multicolumn{2}{|c|}{$\begin{array}{l}\text { natural childbirth } \\
\text { group }\end{array}$} & \multicolumn{2}{|c|}{ cesarean section group } & \multirow[t]{2}{*}{ P Value } \\
\hline & & Mean & (SD) & Mean & (SD) & \\
\hline \multicolumn{2}{|l|}{ Age } & 26.42 & 3.969 & 26.17 & 3.732 & 0.662 \\
\hline \multicolumn{2}{|c|}{ Marriage age } & 22.69 & 3.762 & 22.17 & 3.397 & 0.329 \\
\hline & & $\mathrm{n}$ & $\%$ & $\mathrm{n}$ & $\%$ & \\
\hline \multirow{3}{*}{ Education } & Elementary and middle school & 6 & 85.7 & 1 & 14.3 & \multirow{3}{*}{0.115} \\
\hline & high schooler and Diploma & 41 & 55.4 & 33 & 46.6 & \\
\hline & University & 84 & 67.2 & 41 & 32.8 & \\
\hline \multirow{3}{*}{ Job } & Housewife & 117 & 63.9 & 66 & 36.1 & \multirow{3}{*}{0.698} \\
\hline & Employee & 7 & 53.8 & 6 & 46.2 & \\
\hline & Freelance job & 7 & 70 & 3 & 30 & \\
\hline \multirow{3}{*}{$\begin{array}{l}\text { Husband } \\
\text { Education }\end{array}$} & Elementary and middle school & 14 & 66.7 & 6 & 33.3 & \multirow{3}{*}{0.688} \\
\hline & high schooler and Diploma & 55 & 64.7 & 30 & 35.3 & \\
\hline & University & 62 & 61.4 & 39 & 38.6 & \\
\hline \multirow{4}{*}{$\begin{array}{l}\text { Housing } \\
\text { situation }\end{array}$} & Owner & 54 & 70.1 & 23 & 29.9 & \multirow{4}{*}{0.44} \\
\hline & Rental & 39 & 57.4 & 29 & 42.6 & \\
\hline & Living with family & 34 & 63 & 20 & 37 & \\
\hline & Corporate Homes & 4 & 57.1 & 3 & 42.9 & \\
\hline \multirow[b]{2}{*}{ Insurance } & Yes & 117 & 65 & 63 & 35 & \multirow[b]{2}{*}{0.269} \\
\hline & No & 14 & 53.8 & 12 & 46.2 & \\
\hline \multirow{3}{*}{ Ethnicity } & Persian & 97 & 64.7 & 53 & 35.3 & \multirow{3}{*}{0.33} \\
\hline & Lor & 24 & 55.8 & 19 & 44.2 & \\
\hline & Other & 10 & 76.9 & 3 & 23.1 & \\
\hline
\end{tabular}

Table 2. Survey of Frequency distribution and leveling percentage of attitude toward natural childbirth

\begin{tabular}{llllll}
\hline \multirow{2}{*}{ groups } & \multicolumn{2}{l}{ Natural childbirth } & \multicolumn{2}{l}{ cesarean delivery } \\
& $\mathrm{N}=131$ & \multicolumn{2}{l}{$\mathrm{N}=75$} & \\
\cline { 2 - 5 } Attitude levels & $\mathrm{n}$ & $\%$ & $\mathrm{~N}$ & $\%$ & P Value \\
\hline positive attitude & 71 & 52.2 & 2 & 2.7 & 0.001 \\
Neutral attitude & 60 & 45.8 & 68 & 90.7 & 0.001 \\
Negative attitude & 0 & 0 & 5 & 6.7 & 0.001 \\
\hline
\end{tabular}


Table 3. Comparison of mean and standard deviation of attitudes of first pregnant women toward Preference of Birth Method

\begin{tabular}{llllll}
\hline \multirow{2}{*}{$\begin{array}{lllll}\text { groups } \\
\text { Component of attitude to }\end{array}$} & \multicolumn{4}{l}{ Natural childbirth } & \multicolumn{2}{l}{ cesarean delivery } & \\
\cline { 2 - 5 } $\begin{array}{l}\text { Con } \\
\text { natural childbirth }\end{array}$ & Mean & (SD) & Mean & (SD) & \\
\hline General attitude towards birth method & 164.43 & 32.83 & 134.50 & 13.10 & 0.001 \\
Beliefs and attitudes & 46.77 & 4.74 & 40.03 & 6.11 & 0.001 \\
Childbirth fear & 15.52 & 11.63 & 11.15 & 2.62 & 0.002 \\
Mental, sexual and physical concepts & 31.40 & 5.55 & 25.08 & 4.90 & 0.001 \\
Socio-cultural norms & 22.94 & 2.92 & 20.60 & 2.57 & 0.001 \\
All-round confidence & 23.98 & 24.20 & 15.25 & 3.73 & 0.002 \\
Trust in the delivery agent & 5.43 & 1.56 & 4.61 & 1.42 & 0.001 \\
Performance and personal choice & 8.27 & 1.20 & 7.75 & 1.28 & 0.004 \\
Sources of Influence & 10.13 & 1.92 & 10.04 & 1.91 & 0.752 \\
\hline
\end{tabular}

\section{Discussion}

According to our findings, all domains affecting women's attitude towards natural childbirth influence their choice of delivery method. The results showed a significant difference between the two groups in terms of the mean score of general attitude towards vaginal delivery. In addition, the highest level of attitude in cesarean section was in moderate level and the lowest level was in positive attitude. These results were consistent with the results of the study by Nosratabadi et al. (2018). The highest level of attitude of mothers who had cesarean section before their intervention was moderate. Their intervention was health counseling in the form of individual and group counseling to choose the method of birth [11]. Also in the present study, the attitude level of most participants in the natural childbirth group was positive. In the study of Najafi Sharjabad et al. (2017), the mean score of attitude in natural childbirth group was higher than in cesarean section group [13]. On the other hand, in the study of Akbari et al. (2017), the highest level of attitude for choosing the birth method in pregnant mothers was positive attitude [14]. In their study, the participants were both nulliparous and multiparous, while all participants in our study were nulliparous. According to the results of the present study, socio-cultural beliefs and norms were influential factors in choosing the delivery method. These results were consistent with the results of Bagheri et al. (2012). They concluded in their qualitative study that community culture and beliefs could ultimately influence women's choice of birth method and act as facilitators of vaginal delivery or cesarean delivery [15]. Also, the study by Mohammaditabar et al.'s (2014) showed that normative beliefs are one of the factors that increase the likelihood of choosing cesarean section delivery [16]. Fear of childbirth was another cause of cesarean delivery in the present study, which was in line with the results of the study by Fenwick et al. (2008). They found fear of childbirth as one of the causes of cesarean delivery [17]. Also, in the study of Tavassoli et al. (2015), there was a significant relationship between increased fear of natural childbirth with increased cesarean delivery and decreased fear of childbirth with reduced cesarean delivery and these results were consistent with the results of our study [18]. Also, in Hildingsson's (2014) study, fear of childbirth was strongly associated with cesarean delivery [19]. Ability to perform and choose the method of delivery is another important factor in choosing the delivery method. In the present study, these results were significantly different between the two groups of cesarean and vaginal delivery. These results were consistent with the study of Baghiani Moghaddam et al. (2014) in the area of perceived selfefficacy in the two groups of cesarean and vaginal delivery. In their study, natural childbirth group had higher selfefficacy than cesarean delivery group [20]. The results of our study show that the majority of pregnant women in the cesarean section group and almost half of the pregnant women in the normal childbirth group have a moderate level of attitude towards normal childbirth in the prenatal period. Considering the importance of promoting pregnant women's health, it is recommended that women who do not have a good attitude towards vaginal delivery be properly identified and properly counseled and trained.

\section{Conclusion}

Our findings revealed a direct relationship between the attitude of pregnant women towards vaginal birth and the tendency to normal vaginal delivery and cesarean section. Further research on educational and counseling interventions is recommended. 


\section{Acknowledgments}

This article is the result of a research project approved by Dezful University of Medical Sciences. We thank all individuals contributing to our project.

\section{Financial Support and Sponsorship}

Dezful University of Medical Sciences, Dezful, Iran.

\section{Conflict of Interests}

Authors have no conflict of inter.

\section{References}

[1] Boz, İ., Teskereci, G., \& Akman, G. (2016). How did you choose a mode of birth? Experiences of nulliparous women from Turkey. Women and Birth, 29(4), 359-367. https://doi.org/10.1016/j.wombi.2016.01.005

[2] Abbaspoor Z. (2014). The objective of the factors influencing the choice of delivery method: Development and Psychometric native instruments. PhD of Reproductive health. TMU. Tehran. 2014.

[3] Valizadehberoz, M., \& Ghahremani, J. (2016). Evaluating The Role of Pregnant Womenparticipation in Prenatal Education Classes Inchoosing the Type of Delivery in Zanjan Hospitals. 2016. Retrieved from https://www.sid.ir/en/journal/ViewPaper.aspx?id=532293

[4] Fioretti, B. R. M., Betran, A., \& Torloni, M. (2015). Googling caesarean section: a survey on the quality of the information available on the Internet. BJOG: An International Journal of Obstetrics \& Gynaecology, 122(5), 731-9. https://doi.org/10.1111/1471-0528.13091

[5] Fuglenes, D. O. P., \& Kristiansen, I. S. (2009). Obstetricians' choice of cesarean delivery in ambiguous cases: is it influenced by risk attitude or fear of complaints and litigation? American Journal of Obstetrics and Gynecology, 200(1), 48. e1-. e8. https://doi.org/10.1016/j.ajog.2008.07.021

[6] Hellerstein, S. F. S., \& Duan, T. (2015). China's 50\% caesarean delivery rate: is it too high? BJOG: An International Journal of Obstetrics \& Gynaecology, 122(2), 160-164. http://dx.doi.org/10.1111/14710528.12969

[7] Mazzoni, A. A. F., Liu, N. H., Bonotti, A. M., Gibbons, L., Sanchez, A. J., et al. (2011). Women's preference for caesarean section: a systematic review and meta-analysis of observational studies. BJOG: an international journal of obstetrics \& gynaecology, 118(4), 391-399. https://doi.org/10.1111/j.1471-0528.2010.02793.x

[8] Torloni, M. C. M., Merialdi, M., \& Betran, A. (2014). What do popular S panish women's magazines say about caesarean section? A 21-year survey. BJOG: An International Journal of Obstetrics \& Gynaecology, 121(5), 548-55. https://doi.org/10.1111/j.1471-0528.2010.02793.x

[9] Betrán, A. P., Torloni, M. R., Zhang, J. J., Gülmezoglu, A., Section, W. W. G. C., Aleem, H., et al. (2016). WHO statement on caesarean section rates. BJOG: An International Journal of Obstetrics \& Gynaecology, 123(5), 667-70. https://doi.org/10.1111/1471-0528.13526

[10] Betran, A. P., Torloni, M. R., Zhang, J., Ye, J., Mikolajczyk, R., Deneux-Tharaux, C., et al. (2015). What is the optimal rate of caesarean section at population level? A systematic review of ecologic studies. Reproductive Health, 12(1), 57. https://doi.org/10.1186/s12978-015-0043-6

[11] Nosratabadi, M., Hekmat, K., Dencker, A., \& Abbaspoor, Z. (2018). Individual and Group PsychoEducational Counseling on Knowledge, Attitude and Preference for Birth Method in Nulliparous Women: A Randomized Controlled Trial. Journal of Family \& Reproductive Health, 12(2), 103.

[12] Ghooshchian, S., Dehghani, M., Khorsandi, M., \& Farzad, V. (2011). The role of fear of pain and related psychological variables in prediction of cesarean labor. Arak Uni Med Sci J., 14(56), 45-54.

[13] Najafi-Sharjabad, F., Keshavarz, P., \& Moradian, Z. (2018). Survey on the prevalence and influencing factors for choosing Normal vaginal delivery among pregnant women in Bushehr City, 2015. Community Health Journal, 11(1), 20-9. https://doi.org/10.22123/chj.2018.56094

[14] Akbari, N. M. M., Rakhshani, F., \& Montazeri, A. (2017). Knowledge and attitude of pregnant women towards mode of delivery in Tehran, Iran. Journal of the Iranian Institute for Health Sciences Research, 16(2), 211218.

[15] Bagheri, A., Masoodi-Alavi, N., \& Abbaszade, F. (2012). Effective factors for choosing the delivery method among the pregnant women in Kashan. KAUMS Journal (FEYZ), 16(2), 146-153. Retrieved from 
http://feyz.kaums.ac.ir/article-1-1428-en.html

[16] Mohammaditabar, S., Rahnama, P., \& Mohammadi, K. (2014). Cesarean section on maternal request in Tehran 2010-2011: Incidence and predisposing factors. Journal of Mazandaran University of Medical Sciences, 24(114), 74-82. http://research.shahed.ac.ir/WSR/WebPages/Report/PaperView

[17] Fenwick, J., Gamble, J., Nathan, E., Bayes, S., \& Hauck, Y. (2009). Pre-and postpartum levels of childbirth fear and the relationship to birth outcomes in a cohort of Australian women. Journal of Clinical Nursing, 18(5), 667-677. https://doi.org/10.1111/j.1365-2702.2008.02568.x

[18] Tavassoli, A., Kalari, F., \& Dizji, A. Z. (2015). Social Factors affecting Cesarean Trend in pregnant women. Medical Ethics Journal, 8(29), 145-170. https://www.sid.ir/en/journal/ViewPaper.aspx?id=410964

[19] Hildingsson, I. (2014). Swedish couples' attitudes towards birth, childbirth fear and birth preferences and relation to mode of birth-a longitudinal cohort study. Sexual \& Reproductive Healthcare, 5(2), 75-80. https://doi.org/10.1016/j.srhc.2014.02.002

[20] Baghianimoghadam, M., Baghianimoghadam, M., Hatamzadah, N., Mehrabbik, A., Hashemifard, F., \& Hashemifard, T. (2014). The relationship between HBM constructs and intended delivery method. Tolooebehdasht, 12(4), 105-16. Retrieved from http://tbj.ssu.ac.ir/article-1-1827-en.html

\section{Copyrights}

Copyright for this article is retained by the author(s), with first publication rights granted to the journal.

This is an open-access article distributed under the terms and conditions of the Creative Commons Attribution license (http://creativecommons.org/licenses/by/4.0/). 